\title{
Management of Primary Pulmonary Synovial Sarcoma: A Case Report from Northern Pakistan and Review of Literature
}

\author{
Hadia Fatima*, Jovaria Ehsan, Humera Mahmood and Muhammad Faheem \\ Department of Oncology, Atomic Energy Cancer Hospital \& Nuclear Medicine Oncology and Radiotherapy Institute, Pakistan
}

Submission: November 19, 2018; Published: November 28, 2018

*Corresponding author: Hadia Fatima, Resident Oncology, Atomic Energy Cancer Hospital \& Nuclear Medicine Oncology and Radiotherapy Institute, Islamabad, Pakistan

\begin{abstract}
Primary pulmonary synovial sarcoma is a rare lung tumor and has mesenchymal origin. It is difficult to diagnose clinically and should be differentiated from other primary and metastatic lung tumors. The definitive diagnosis should be made via careful histopathological evaluation along with immunohistochemistry. Cytogenetic studies detect SYT-SSX-1 variant which has got diagnostic and prognostic value. The disease has poor outcome and complete cure is difficult to achieve. We hereby report a case of 40 years old female who was diagnosed and treated for metastatic primary pulmonary synovial sarcoma at Atomic Energy Cancer Hospital, NORI.
\end{abstract}

Keywords: Primary pulmonary synovial sarcoma; Lung; Immunohistochemistry

\section{Introduction}

Primary pulmonary synovial sarcoma (PPSS) is an extremely unusual malignancy associated with aggressive behavior and poor clinical outcome [1]. The tumor originates from mesenchymal cells [1]. Synovial sarcomas make up to $8 \%$ of soft tissue sarcomas most commonly seen in extremities [1]. Pulmonary sarcomas are even rare making up to just $0.1-0.5 \%$ of primary lung malignancies [2]. The differential diagnosis includes metastatic sarcomas and another primary lung cancer [3]. Primary pulmonary synovial sarcoma behaves like soft tissue synovial sarcoma [4]. PPSS may arise from lung parenchyma, pleura, chest wall and mediastinum [5].

The molecular analysis shows characteristic chromosomal translocation $\mathrm{t}(\mathrm{x} ; 18)$ which confirms diagnosis in up to $90 \%$ patients and is also a poor prognostic feature [6]. In the rest of $10 \%$ cases diagnosis is established through histopathology along with immunohistochemistry [6]. The disease has predilection for young male patients [5]. Our patient was 40-year-old female who presented with cough associated with hemoptysis. She was diagnosed with Stage IV PPSE and received palliative chemotherapy. Only few such cases have been reported in the literature so far and no case has been previously reported from Northern Pakistan.

\section{Case Report}

A 40-year-old female patient, non-smoker and non-addict, known diabetic and hypertensive controlled on oral medication and with past surgical history of cholecystectomy for gallstones and hysterectomy for fibroid uterus presented with complaint of dry cough for 4 months. It was later associated with hemoptysis. On examination, patient had a good performance status. Chest examination showed decreased bilateral air entry in lungs, bilateral breast examination was unremarkable and there was no axillary and cervical lymphadenopathy. Rest of the systemic examination was normal.

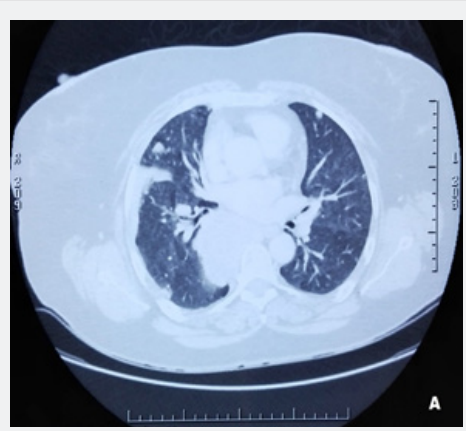

Figure 1: CT scan chest (lung window) showing multiple soft tissue density intrapulmonary and pleural based nodules in bilateral lung fields.

She was investigated, and CT scan chest and abdomen was done that showed bilateral innumerable nodular opacities both intrapulmonary as well as pleura based, of variable sizes (Figure 1). Largest intrapulmonary mass in right upper lobe measured 6 x $5.1 \mathrm{~cm}(\mathrm{AP} \times \mathrm{TR})$ and large pleura-based mass along right lung 
measured 9 x $4.8 \mathrm{~cm}$ (AP x TR) (Figure 2). Liver showed a large cyst in segment IV measuring 5.3 x $5.4 \mathrm{~cm}$ (AP x TR) (Figure 3). There was no evidence of any breast mass lesion and axillary lymphadenopathy. No focal osseous lesion was seen.

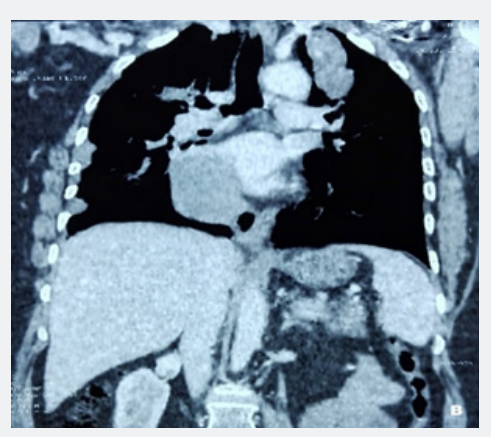

Figure 2: CT scan chest showing centrally placed heterogeneously enhancing mass in right lung.

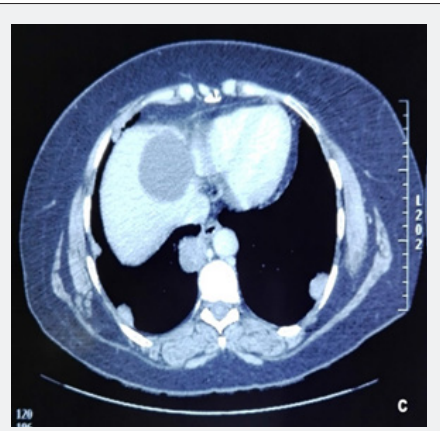

Figure 3: CT scan upper abdomen showing well defined cyst in liver.

PET scan was done that showed hypermetabolic soft tissue lesions involving upper lobes of both lungs, the largest one occupying right lung with SUV of 6.8. Hypermetabolic posterior pericardiac lymph nodes were observed. There were numerous pleural and parenchymal deposits in bilateral lungs. There was no evidence of hypermetabolic hepatic and osseous metastasis.

Patient underwent right lung upper lobe wedge resection. The specimen consisted of two grey white linear cores, largest core measuring $0.8 \times 0.1 \mathrm{~cm}$ and smaller core measured 0.3 $x 0.1 \mathrm{~cm}$. Microscopic examination revealed spindle shaped neoplastic cells arranged in short fascicles with interspersed blood vessels. Unremarkable lung parenchyma was identified. Foci of entrapped pulmonary glandular stricture were also seen close to the edge of the lesion. The mitotic activity was low with less than 4 mitosis/10 HPF. No pleomorphism was seen. Immunohistochemistry revealed that tumor cells were immunopositive for WT-1, TLE-1, Bcl-2 and CD-99 while EMA, Cytokeratin AE1/AE3, Cytokeratin 7, Cytokeratin 19, GATA-3, CD 34, STAT-6, S-100 and Sox-10 were negative. The diagnosis of Monophasic Synovial Sarcoma of lung was made.

The case was discussed in multidisciplinary tumor board and the patient was planned for palliative chemotherapy. Echocardiography was advised to the patient that was normal with ejection fraction of $65 \%$. The patient was started on combination chemotherapy with Iphosphamide and Doxorubicin combination along with Mesna in 3 weekly protocol. Patient received 6 cycles of chemotherapy with remarkable subjective and radiological response. The patient was kept on close follow up. She remained asymptomatic for 6 months after which she presented again with complaint of right hypochondrial pain.

CT scan repeated showed a large pleura based heterogeneously enhancing soft tissue density mass lesion along right para-vertebral region extending superiorly from $\mathrm{T} 6$ vertebral body to T9-10 intervertebral disc level inferiorly, adjacent to superior segment of right lower lobe measuring 71 x $61 \mathrm{~mm}$ associated with loculated pleural effusion tracking in to right oblique fissure with associated fissural thickening (Figure 4). Multiple intrapulmonary and pleura based soft tissue density nodules of varying sizes were noted in bilateral lung fields with some of them showing cavitation. Hepatic cyst in the liver was static. Traction bronchiectatic changes were noted in anterior segment of right upper lobe (Figure 5).

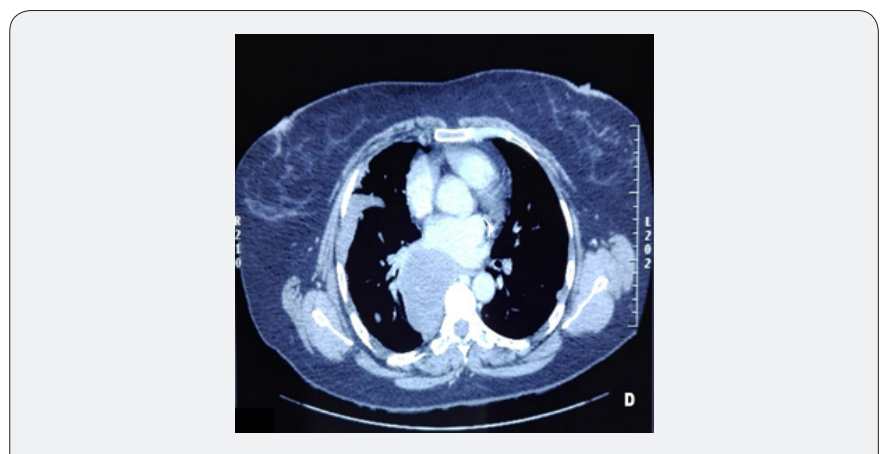

Figure 4: CT scan chest (mediastinal window) showing right lung mass along with ipsilateral loculated pleural effusion.

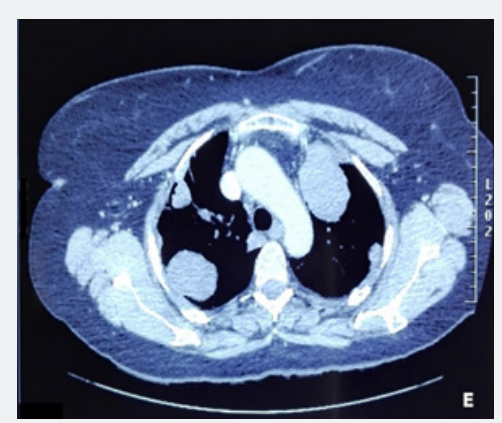

Figure 5: CT scan chest showing bilateral soft tissue density nodules along with a band of traction bronchiectasis.

Repeat echocardiography for ejection fraction was normal. Patient was counseled thoroughly about the advanced nature of the disease and poor prognosis and was planned for second line chemotherapy.

\section{Discussion}

Thoracic primary synovial sarcomas are very rare neoplasms mostly originating from lung, heart, mediastinum and esophagus [1]. The incidence of primary pulmonary synovial sarcomas is very low with male predominance [5]. WHO classifies the disease as mesenchymal tumor with most common sites of origin being 
lung parenchyma, tracheobronchial tree and pulmonary artery [3]. The patients usually present with cough, chest pain, dyspnea and hemoptysis and usually not associated with smoking [5]. Although it resembles more to soft tissue counterpart but is difficult to diagnose clinically and radiologically from other primary and metastatic lung tumors [4]. Our patient was a 40-year-old non-addict female, presented with complaints of cough and hemoptysis. The primary lung mass was centrally placed in right para-vertebral location.

PPSE has four histological variants including spindle cell monophasic, epithelial cell monophasic, biphasic that includes both spindle and epithelial components and poorly differentiated small round cell forms $[3,5]$. The monophasic subtype is most common [3,5]. The gross morphology of tumor commonly consists of interlacing fascicles, dense cellularity, hyalinized stroma and increased vascularity [7]. In our patient tumor comprised of spindle cells arranged in fascicles among interspersed blood vessels, foci of pulmonary glandular architecture and low mitotic count.

The definitive diagnosis is made via immunohistochemical staining. The frequent common immunostains are epithelial membrane antigen, CD99, Bcl-2, Calponin, Cytokeratins and Vimentin but may also show weak positivity for S100 and CD34 $[3,5]$. Recently cytogenetic studies are also being performed for definitive diagnosis of synovial sarcomas which detects translocation $\mathrm{t}(\mathrm{X}$; 18) (p11.2; q11.2) secondary to fusion of the SYT gene on chromosome 18 to SSX1 or SSX2 on chromosome X [1]. In our patient diagnosis was made through histopathology along with immunohistochemistry. The patient was diagnosed as a case of monophasic synovial sarcoma of lung with positive WT-1, TLE-1, Bcl-2 and CD-99 and negative for EMA, Cytokeratin AE1/AE3, Cytokeratin 7, Cytokeratin 19, GATA-3, CD34, STAT-6, S-100 and Sox-10 immunostains.

Radiological findings are consistent with well-defined soft tissue density heterogeneously enhancing mass lesion with necrosis and no calcification can be appreciated on CT scan and PET scan [2]. Ipsilateral pleural effusion is quite frequently seen while hilar and mediastinal lymphadenopathy is rare $[2,5]$. Tumor hemorrhage and extension into chest wall can also be seen in some cases which makes it different from rest of the lung tumors [2]. In our patient the CT scan showed right sided lung mass with metastatic deposits in both lungs along with loculated pleural effusion on ipsilateral side and there was no lymphadenopathy. PET scan showed hypermetabolic lesions in bilateral lung fields with largest one on right side along with posterior pericardiac lymph nodes.

If detected early, adequate resection of the tumor with negative margins followed by adjuvant chemotherapy is the mainstay of treatment $[3,8]$. Iphosphamide and doxorubicinbased chemotherapy improves overall survival up to $24 \%$ in patients of synovial sarcoma when given in adjuvant setting [8]. Radiotherapy has no definite role in improving overall and progression free survival [3]. Pazopanib is a targeted agent that also has got some survival benefit [9]. Our patient had presented with advanced disease in which curative therapy was not possible. She was given iphosphamide and doxorubicin combination in palliative setting and disease did not progress for almost 6 months.

The disease has poor prognostic outcome with 2-year recurrence free survival of $35.7 \%$ and 5-year overall survival of up to $50 \%[1,2]$. Limited data is available on the natural history of the disease and its course due to its rarity [10]. However, in patients who are diagnosed with metastatic disease, the mortality and morbidity rate are very high. Our patient was diagnosed with stage IV primary pulmonary synovial sarcoma.

\section{Conclusion and Recommendations}

The primary pulmonary synovial sarcoma is an extremely rare malignancy and is a diagnostic as well as a therapeutic challenge. Radiologists and histopathologists should report carefully keeping rare disease presentations in mind so that correct diagnosis can be made. Such cases should be discussed in multidisciplinary tumor boards for most appropriate management plan.

\section{References}

1. Dennison S, Weppler E, Giacoppe G (2004) Primary pulmonary synovial sarcoma: a case report and review of current diagnostic and therapeutic standards. The Oncologist 9(3): 339-342.

2. Kim GH, Kim MY, Koo HJ, Song JS, Choi CM (2015) Primary pulmonary synovial sarcoma in a tertiary referral center: clinical characteristics, CT, and 18F-FDG PET findings, with pathologic correlations. Medicine (Baltimore) 94(34): e1392.

3. Chang CC, Chang PY (2018) Primary pulmonary synovial sarcoma. Journal of Cancer Research and Practice 5(1): 24-26.

4. Terasaki H, Niki T, Hasegawa T, Yamada T, Suzuki K, et al. (2001) Primary synovial sarcoma of the lung: a case report confirmed by molecular detection of SYT-SSX fusion gene transcripts. Japanese journal of clinical oncology 31(5): 212-216.

5. Roy PP, Das A, Sarkar A, Dwari AK, Datta S (2012) A primary synovial sarcoma of lung. N Am J Med Sci 4(5): 241-243.

6. Seyhan EC, Sokucu SN, Gunluoglu G, Veske NS, Altin S (2014) Primary pulmonary synovial sarcoma: a very rare presentation. Case Reports in Pulmonology 2014(537618): 3.

7. Hartel PH, Fanburg-Smith JC, Frazier AA, Galvin JR, Lichy JH, et al. (2007) Primary pulmonary and mediastinal synovial sarcoma: a clinicopathologic study of 60 cases and comparison with five prior series. Mod Pathol 20(7): 760-769.

8. Spillane AJ, A'hern R, Judson IR, Fisher C, Thomas JM (2000) Synovial sarcoma: a clinicopathologic, staging, and prognostic assessment. J Clin Oncol 18(22): 3794-3803.

9. van der Graaf WT, Blay JY, Chawla SP, Kim DW, Bui-Nguyen B, et al. (2012) Pazopanib for metastatic soft-tissue sarcoma (PALETTE): a randomised, double-blind, placebo-controlled phase 3 trial. The Lancet 379(9829): 1879-1886.

10. Belbaraka R, Ismaili N (2014) Primary sarcoma of the lung: A very rare diagnosis and poor prognosis. Clinical Cancer Investigation Journal 3(2): 176-178. 
Your next submission with Juniper Publishers will reach you the below assets

- Quality Editorial service

- Swift Peer Review

- Reprints availability

- E-prints Service

- Manuscript Podcast for convenient understanding

- Global attainment for your research

- Manuscript accessibility in different formats

( Pdf, E-pub, Full Text, Audio)

- Unceasing customer service

Track the below URL for one-step submission https://juniperpublishers.com/online-submission.php 